\title{
ELEMENTOS PRÉ-MOLDADOS UTILIZADOS EM SILOS PRISMÁTICOS, MODULARES DE CONCRETO ARMADO
}

\author{
PREFABRICATED MULTICELLS SILOS MODULES IN CONCRETE
}

\author{
Eduardo Teixeira da SILVA ${ }^{1}$
}

\begin{abstract}
RESUMO
Este trabalho foi desenvolvido com o objetivo de fornecer subsídios técnicos para projetos de silos multicelulares em concreto armado, pré-moldados, de forma quadrada, com capacidade de 60 t ou $15 \mathrm{t} \mathrm{de}$ milho por célula para atender a pequenos e médios produtores. Foram feitas análises teóricas e experimentais em um modelo de elemento a fim de se avaliar o comportamento estrutural do elemento isolado e encaixado, em escala natural, que formam as paredes de silos prismáticos, modulares. Com base nas análises experimentais realizadas, concluiu-se que o modelo de encaixe utilizado entre dois elementos (tipo machofêmea) comportou-se de maneira positiva, conferindo maior rigidez à região entre os elementos. As tensões calculadas pelo método simplificado RAVENET e teoria de vigas bi-articuladas subestimaram as tensões experimentais. Os deslocamentos medidos apresentaram comportamento similar, porem superiores aos deslocamentos calculados pela flecha máxima e flecha no meio do vão.
\end{abstract}

Palavras-chave: Silos, Construções Rurais, Pré-Moldados, Silos Multicelulares.

\begin{abstract}
This research work was developed to provide technical information for designing multicells reinforced concrete prefabricated silos, in square form and 60 tons to 15 tons corn capacity per cell, aiming small and medium agricultural producers. Theoretical and experimental analyses were conducted that the two coupled by appluing a model of element to evaluate the strutural behavior of a real scale separated elements and coupled elementand coupled element which form the square wall of the modular silo. From the experimental analysis it was concluded that the two coupled element model presented a satisfactory behavior where toughest spot. The stress values obtained from the RAVENET'S method and from the biarticulable beam theory were lower than the values experimentally obtained. The measured displacement exhibited similar behavior, however greater than the values calculated by applying the maximum inflection and the half shaft inflection method.
\end{abstract}

Key-words: silos, rural building, pre-cast, silos mult-cell.

${ }^{1}$ Prof. Dr. do Depto. de Solos da Universidade Federal do Paraná - Rua dos Funcionários 1540 Cabral - Curitiba, Pr CEP $80035-050$ eduardo@agrarias.ufpr.br - Tel. (41) 3505667. 
SILVA, E.T. Elementos pré-moldados utilizados em silos...

\section{INTRODUÇÃO}

Os silos são instalações rurais ou industriais que possuem, como finalidade básica, armazenar produto sólido, granular ou pulverulento a granel, possibilitando o mínimo de influência do meio externo com o ambiente de estocagem, a fim de manter inalteradas as características físicas, químicas e biológicas do produto, durante o período de armazenagem.

Para a produção de grãos que se precisa atingir nos próximos anos com a finalidade de suprir a demanda interna e o crescimento populacional, há necessidade de investimentos em armazenagem de boa qualidade, localizada de forma estratégica, inclusive com prioridade para as unidades ao nível de pequeno e médio produtor. Os silos, para pequenos e médios produtores, vêm sendo construídos com materiais e técnicas convencionais de construção, utilizando principalmente a alvenaria de tijolos, por proporcionarem menores custos em relação aos silos metálicos industrializados. Tem-se que destacar que as perdas dos produtos armazenados são muito influenciadas pela qualidade das instalações.
Objetiva-se com o presente trabalho, fornecer subsídios técnicos para projetos de silos multicelulares em concreto armado, pré-moldado, modulares, de forma poligonal quadrada com capacidade de armazenamento de $60 \mathrm{t}$ ou $15 \mathrm{t}$ por célula, com alternativa para atender a pequenos e médios produtores. Adicionalmente, pretende-se obter informações que contribuam para o desenvolvimento da futura norma brasileira para silos.

\section{MATERIAL E MÉTODOS}

Foi utilizado um modelo teórico de silo para os cálculos das pressões, utilizado as propriedades físicas do milho, sendo este modelo composto de quatro células, com capacidade de armazenamento de $15 \mathrm{t}$ em cada célula, perfazendo um total de $60 t$ de produto armazenado. A célula possui altura de $8,5 \mathrm{~m}$, vão de $1,5 \mathrm{~m}$, com 17 elementos sobrepostos (Figura 1).

Os elementos foram dimensionados seguindo os procedimentos de cálculo e recomendações praticas estabelecidas pela Norma Americana ACl-313 (1983), para o projeto de paredes.
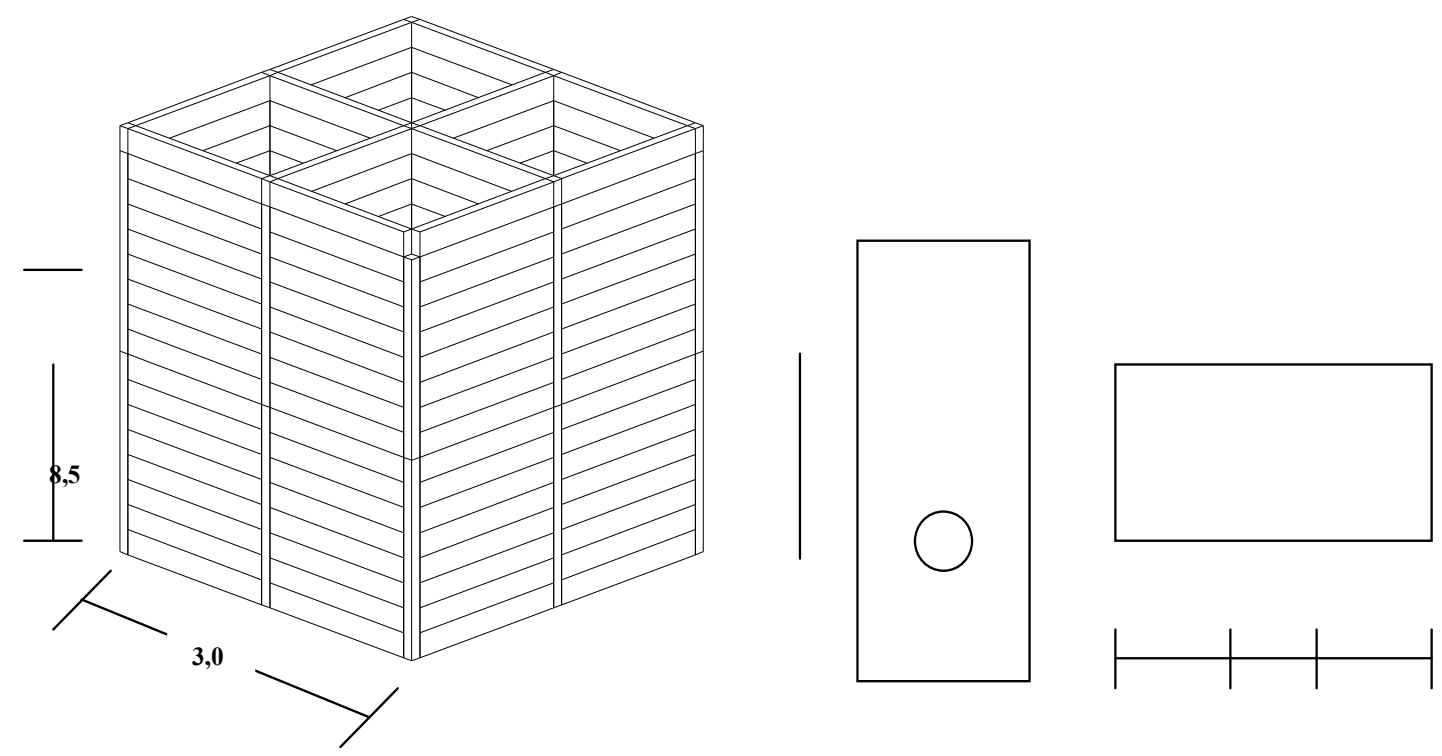

FIGURA 1 - Modelo de silo utilizado com 4 células de 17 elementos (1,5 X 0,5 m), corte transversal e dimensões dos encaixes utilizados em cada elemento. 
A ACl-313 (1983) estabelece que a espessura mínima para paredes de silos pré-moldados de concreto armado não deve ser inferior a 2" $(0,05 \mathrm{~m})$, adotou-se a espessura de $0,08 \mathrm{~m}$. Os elementos foram armados com malha dupla de aço CA-60, diâmetro nominal de $0,063 \mathrm{~m}$, espaçamento horizontal de $0,1175 \mathrm{~m}$ entre barras e vertical de $0,144 \mathrm{~m}$, mantendo um recobrimento de $0,02 \mathrm{~m}$ em cada face.

Utilizou-se em todos os elementos um tipo de encaixe adotado por Ravenet (1992), onde os elementos apresentavam em sua extremidade superior e inferior um ressalto na forma de um semicírculo em toda extensão do comprimento e, de maneira inversa, na extremidade inferior, a fim de servir de encaixe tipo macho-fêmea, com um raio médio de $0,01 \mathrm{~m}$, conforme pode ser visto na Figura 1.

Foi demarcada uma malha sobre a superfície dos elementos, procurando-se estabelecer os pontos onde seriam instalados os extensômetros elétricos de resistência e os transdutores diferenciais. Esta maIha foi composta de linhas pré-estabelecidas da seguinte forma:

- Ensaio com um único elemento: três linhas horizontais, duas instaladas a $50 \mathrm{~mm}$ das extremidades inferior e superior e uma no centro de cada elemento, independente do seu comprimento; três linhas verticais, duas instaladas a $1 / 3$ de cada extremidade e uma no centro do elemento.
- Ensaio com dois elementos encaixados: duas linhas horizontais, uma no centro e outra a $50 \mathrm{~mm}$ da extremidade próxima a região de encaixe; três linhas verticais, duas instaladas a $1 / 3$ de cada extremidade e uma no centro.

Como o sistema de aquisição de dados utilizado apresentava um limite de 16 canais para leituras, adotou-se o seguinte critério quanto aos pontos de medições:

- 9 pontos para strain gauges e 7 pontos para LVDT's para elementos isolados.

- 8 pontos para strain gauges e 8 pontos para LVDT's para elementos encaixados.

Os ensaios com os elementos pré-moldados de concreto foram realizados de duas maneiras distintas: inicialmente ensaiou-se apenas um elemento de maneira isolada, em seguida ensaiou-se outros dois elementos encaixados, Figuras 2 e 3.

O carregamento dos elementos foi realizado através de macaco hidráulico com intervalos distintos de cargas monitoradas, controladas por dinamômetro e pelo sistema de aquisição de dados da seguinte maneira:

- Um elemento de $1,5 \mathrm{~m}$ de vão: cargas de aproximadamente $1,08 \mathrm{kPa}$, até a carga correspondente a $8,92 \mathrm{kPa}$, instante em constatou-se o aparecimento de fissura no elemento, através de observação visual.

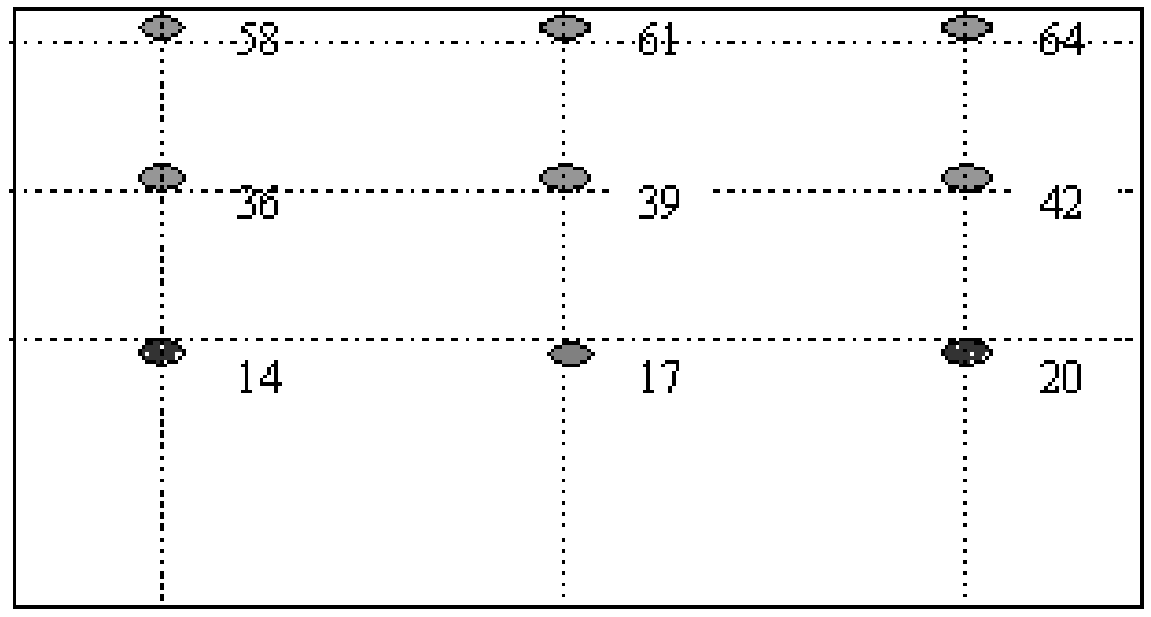

FIGURA 2 - Malha de pontos para colagem dos strain gauges e instalação dos medidores de deslocamento (LVDT's). Os símbolos $\bigcirc$ identificam os pontos de colagem do strain gauges e os símbolos os pontos de instalação dos medidores de deslocamentos. 
SILVA, E.T. Elementos pré-moldados utilizados em silos...

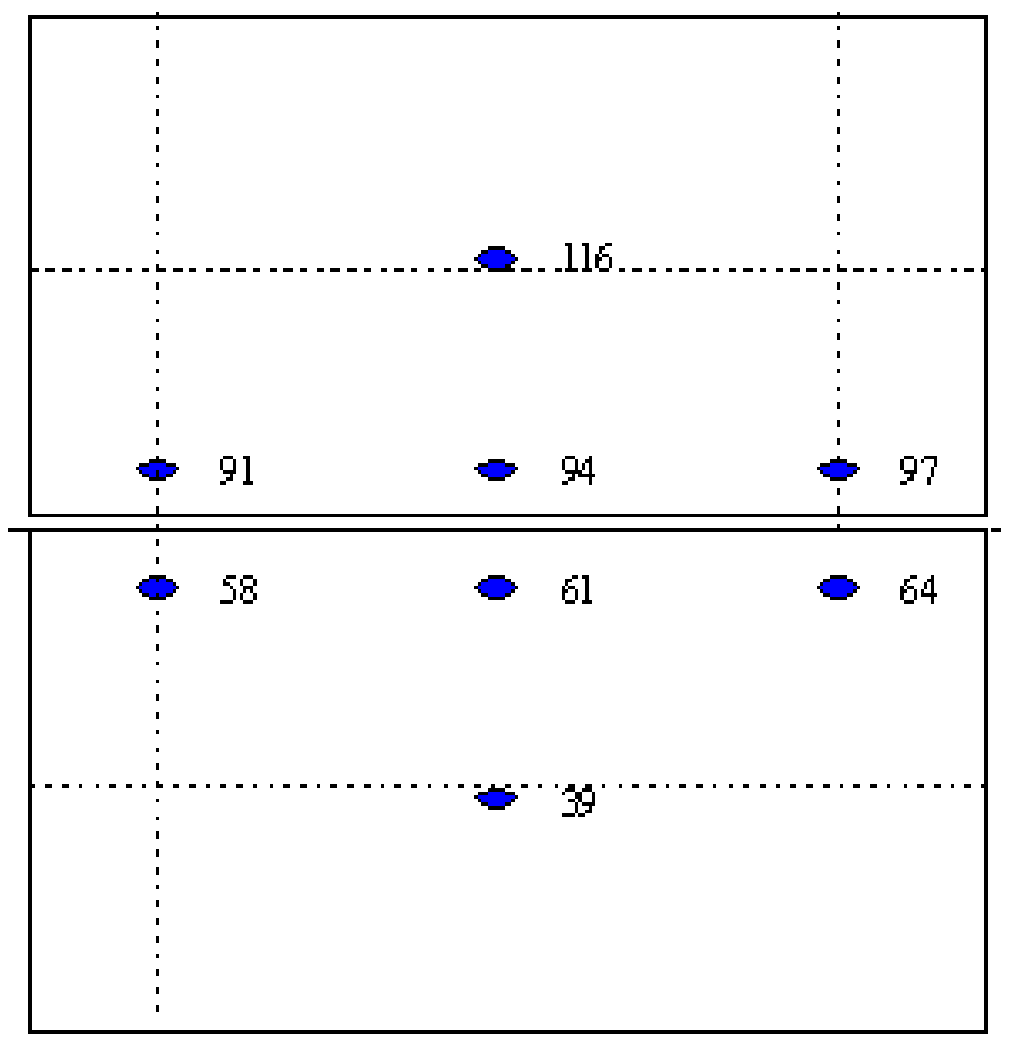

FIGURA 3 - Malha de pontos para colagem dos strain gauges e instalação dos medidores de deslocamento (LVDT's) nos elementos encaixados. Os símbolos: -identificam os pontos de colagem de strain gauges e instalação dos medidores de deslocamento nos elementos encaixados.

- Dois elementos de 1,5m de vão, encaixados: cargas de aproximadamente $4,9 \mathrm{kPa}$, até a carga correspondente a $27,06 \mathrm{kPa}$, instante em constatou-se o aparecimento de fissura no elemento, através de observação visual.

Para realização dos ensaios com os elementos, em laboratório, os medidores de deformações (strain gauges) e os medidores de deslocamento (LVDT's) foram acoplados a um sistema de aquisição de dados, com 16 canais para entrada de sinais, modelo LYNX, via interface paralela de um microcomputador "Notebook"

\section{RESULTADOS E DISCUSSÃO}

\section{Tensões}

As tensões foram analisadas no sentido longitudinal dos elementos, ou seja, no sentido do vão, sentido no qual ocorrem as maiores tensões neste tipo de silo, como também, sentido em que se calculam as tensões pelo método simplificado e teoria de vigas bi-articuladas; desta forma pode-se confrontar os resultados teóricos. Na Figura 4, são apresentadas as curvas das tensões obtidas pelo método simplificado Ravenet, teoria de vigas bi-articuladas e as tensões experimentais obtidas. A pressão de $8,92 \mathrm{kPa}$ representa o instante em que observou-se o aparecimento de fissura no elemento de 1,5 de vão. Os pontos de medições apresentaram valores próximos para tensões durante o carregamento do elemento até a carga de 7,84 kPa; a partir desta, estes pontos passaram a ter comportamento diferente entre si. Os valores de tensões teóricos (RAVENET 1992, e teoria de vigas) apresentam comportamento similar ao longo do carregamento, porém, quando comparados com os dados experimentais, apresentam valores inferiores, o que significa dizer que os valores teóricos subestimam as tensões no elemento. A pressão de $27,06 \mathrm{kPa}$, (Figura 5) representa o instante em que observou-se o aparecimento de fissura no elemento encaixado de 1,5 m de vão, valor este superior ao do elemento ensaiado isolado $8,92 \mathrm{kPa}$, o que representa um aumento de 3,03 vezes na carga aplicada, para um aumento de apenas 2 vezes na área de contato. 
SILVA, E.T. Elementos pré-moldados utilizados em silos...

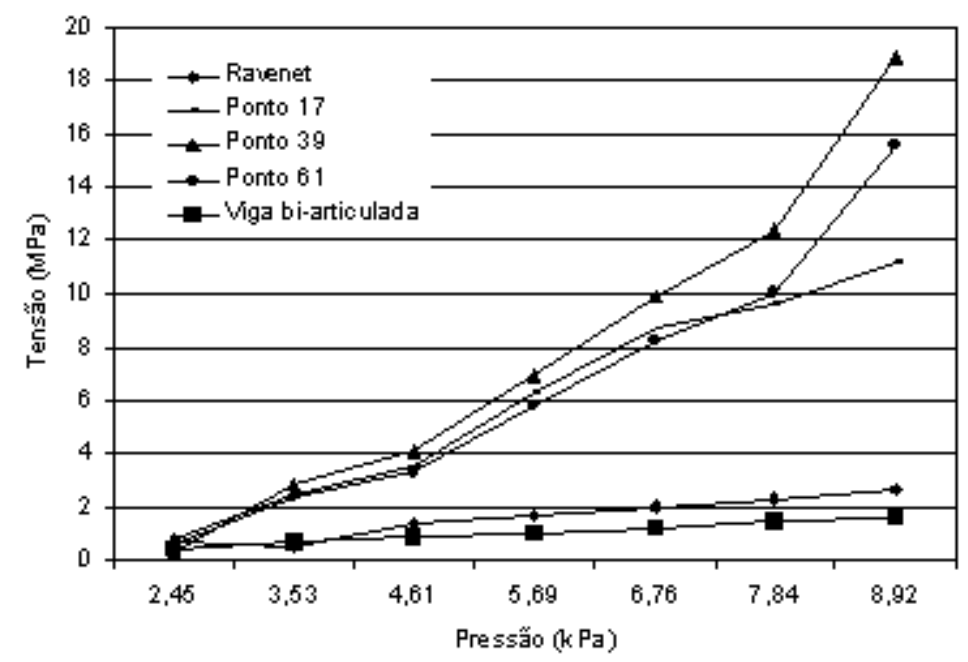

FIGURA 4 - Tensões experimentais e calculadas para um elemento.

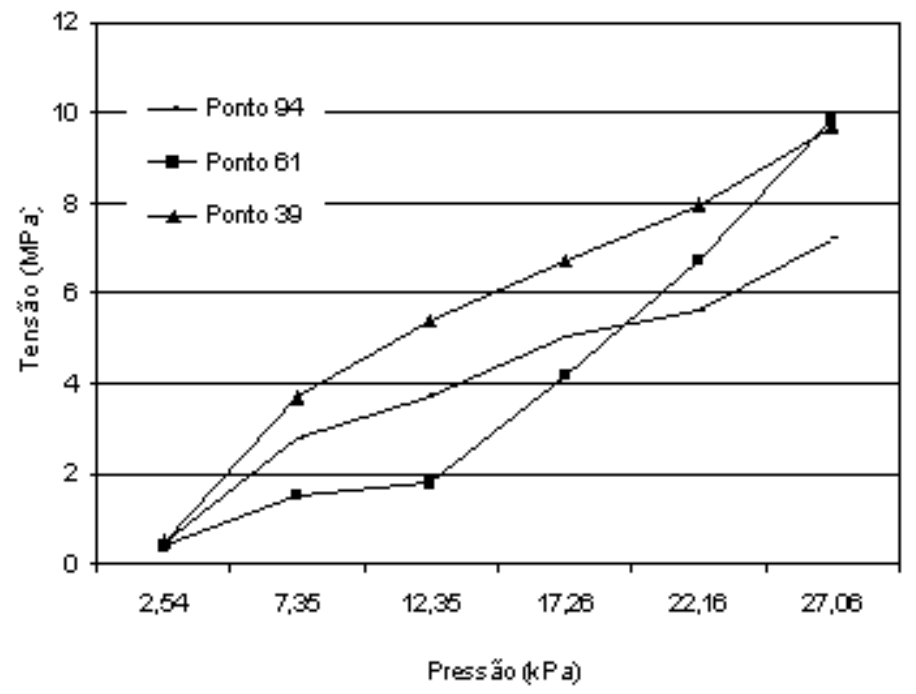

FIGURA 5 - Tensões experimentais determinadas em um elemento.

\section{Deslocamentos}

A Figura 6 mostra os deslocamentos do elemento de 1,5 m de vão, para os pontos experimentais, calculados no meio do vão e flecha máxima. Pode-se verificar que o ponto 17 comportou de maneira distinta aos demais pontos experimentais e deslocamentos calculados, apresentando valores inferiores aos demais para todos os valores de pressão aplicada. Os pontos 39 e 61 apresentaram comporta- mento similar, próximo aos valores dos deslocamentos calculados (f. máx. e f. calc. meio do vão); o ponto 61 apresentou os maiores valores principalmente a partir da pressão aplicada correspondente a 6,76 $\mathrm{kPa}$ em relação aos demais. Como a verificação do aparecimento de fissura era feita visualmente, acredita-se que tenha ocorrido o fissuramento do elemento no instante de aplicação correspondente a pressão de $6,76 \mathrm{kPa}$. 
SILVA, E.T. Elementos pré-moldados utilizados em silos...

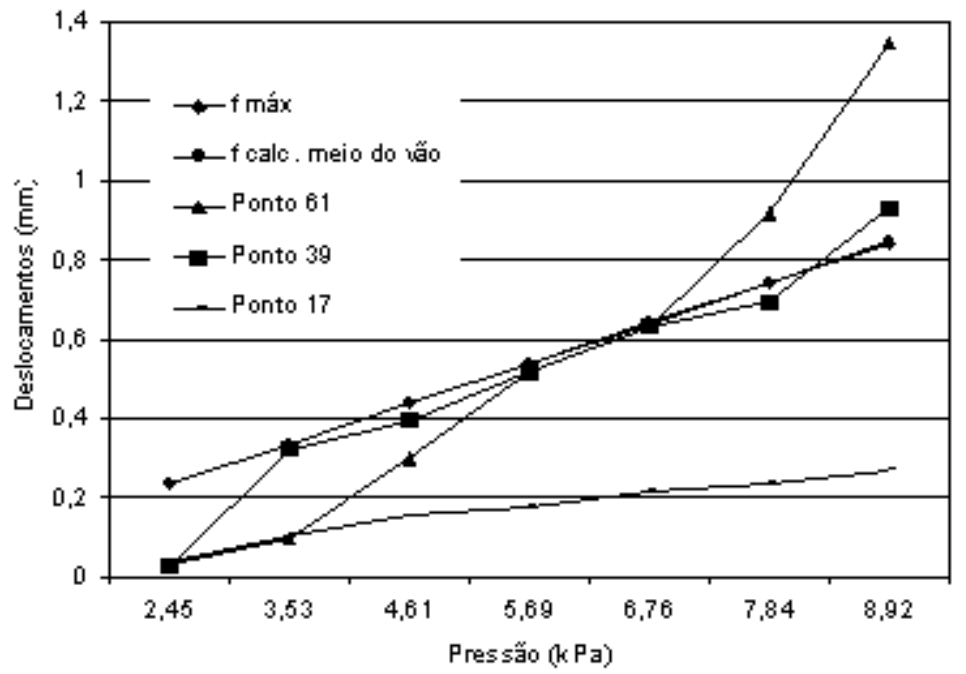

FIGURA 6 - Deslocamentos experimentais e calculadas em um elemento.

Para o caso dos elementos encaixados de 1,5 $\mathrm{m}$ de vão, (Figura 7) pode-se verificar que os pontos localizados no centro de cada elemento apresentaram os maiores deslocamentos; com o ponto 116 apresentando o maior deslocamento entre todos os pontos dos elementos encaixados, seguidos do ponto 39 e 94 , com o ponto 61 apresentando o menor desloca- mento entre todos. Os pontos localizados próximos a região de encaixe entre os dois elementos apresentaram comportamento similar, mesmo com o ponto 61 apresentam deslocamento inferior, enferindo-se que o encaixe utilizado tenha causado efeito positivo, reduzindo o deslocamento nesta região.

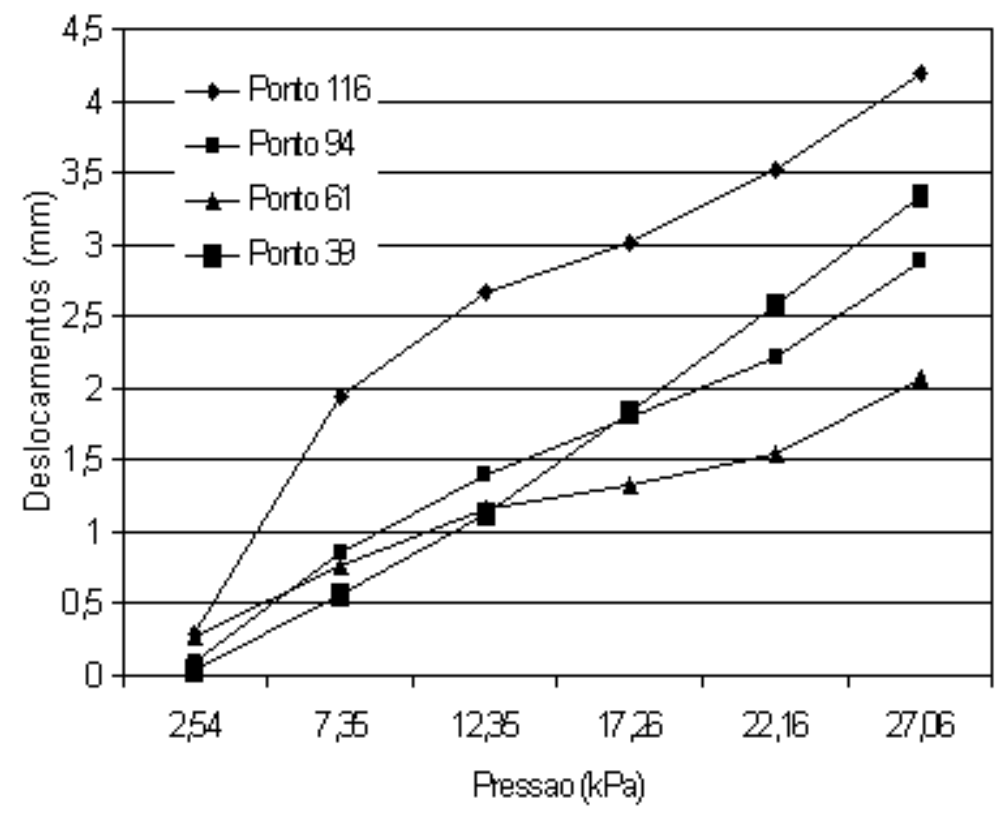

FIGURA 7 - Deslocamentos experimentais e calculados dois elementos encaixados. 
SILVA, E.T. Elementos pré-moldados utilizados em silos...

\section{CONCLUSÕES}

- O uso de elementos de paredes em silos de concreto armado, com forma poligonal quadrada, apresenta vantagens estruturais, construtivas e funcionais. Os elementos analisados apresentaram resultados bastante satisfatórios em termos de resistência, mostrando-se adequados a esta finalidade para os dois modelos estudados.

- As tensões calculadas pelo método simplificado Ravenet e teoria de vigas bi-articuladas subestimam as tensões do elemento de $1,5 \mathrm{~m}$ de vão; a tensão determinada no ponto 39 foi cerca de 16,25 e $17,27 \mathrm{MPa}$ superior as calculadas pelo método sim- plificado e teoria de vigas bi-articuladas, respectivamente, para a pressão onde observou-se o aparecimento de fissura no elemento.

- Os deslocamentos medidos apresentaram comportamento similar aos deslocamentos calculados pela flecha máxima e flecha no meio do vão; os deslocamentos calculados foram superiores aos deslocamentos medidos.

- O modelo de encaixe utilizado (tipo machofêmea), comportou-se de maneira positiva, pois os pontos de medições de deslocamentos e deformações próximos à região de encaixe entre os elementos apresentaram valores aproximadamente similares aos medidos nos pontos centrais dos elementos.

\section{REFERÊNCIAS BIBLIOGRÁFICAS}

1 AMERICAN CONCRETE INSTITUTE. Recommended practice for design and construction of concrete bins, silos and bunkers for storing granular materials. New York, 1983. pags 11.

2 RAVENET, J. Silos. Barcelona: J. Ravenet, 1992. 508p. 